\title{
TRANSIÇÃO DO PARADIGMA TECNOLÓGICO E A INSERÇÃO DA ECONOMIA BRASILEIRA EM CONTEXTO GLOBAL
}

\section{TECHNOLOGICAL PARADIGM TRANSITION AND THE BRAZILIAN ECONOMY INSERTION ON GLOBAL CONTEXT}

\author{
Guilherme Nunes Pires ${ }^{1}$ \\ João Victor Souza da Silva ${ }^{1}$
}

\begin{abstract}
Recebido em: 18/08/2017 Aceito em: 04/10/2017 gnpires@hotmail.com
\end{abstract}

Resumo: O intuito do artigo é compreender como ocorreu a inserção da economia brasileira contemporânea diante da transição do paradigma fordista para o microeletrônico. Para isso, serão expostas as características da economia brasileira durante sua fase de industrialização e sob o paradigma metalomecânico-químico (1930-80). Com o processo de reestruturação produtiva global, iniciado nos anos 1980, a economia nacional apresentou queda elevada da participação da indústria no produto. Sua participação nas Cadeias Globais de Valor (CGV) tem como papel predominante o fornecimento de produtos intensivos em recursos naturais e de baixo valor adicionado. Sintetiza-se que a estrutura produtiva interna do Brasil foi condicionada por sua posição no comércio internacional, seja em seu período áureo de industrialização ou nas décadas recentes. A complexidade produtiva se sujeitou à manutenção de exportações de bens não industriais ou de indústria de baixa intensidade tecnológica. A metodologia utilizada foi revisão crítica de literatura e análise de dados secundários.

Palavras-chave: Paradigma tecnológico. Reestruturação produtiva. CGV.

Abstract: The aim of the article is to understand how the insertion of the contemporary Brazilian economy occurred in the face of the transition from the fordist paradigm to the microelectronic. Thus, will be exposed the characteristics of the Brazilian economy during its industrialization phase and under the metal-mechanical-chemical paradigm (1930-80). With the process of global productive restructuring begun in the 1980s, the national economy showed a high drop in the share of industry in the product. Its participation in the Global Value Chains (GVC) has a predominant role in supplying products that are resource intensive and low value added. It is synthesized that Brazil's internal productive structure was conditioned by its position in international trade, whether in its golden period of industrialization or in recent decades. The production complexity was subject to the maintenance of exports of nonindustrial goods or low intensity industry technological. The methodology used was critical review of literature and analysis of secondary data.

Keywords: Technological paradigm. Productive restructuring. GVC.

\footnotetext{
${ }^{1}$ Universidade Federal de Santa Maria - UFSM - Santa Maria - Rio Grande do Sul - Brasil.
} 


\section{INTRODUÇÂO}

Contemporaneamente, as análises das estruturas produtivas dos países fornecem uma chave para entender o porquê de uma determinada economia ser mais dinâmica, competitiva e rica. Uma estrutura produtiva baseada em uma ampla gama de processos complexos na produção de bem, favorece melhor dinamismo, maior tecnologia e valor agregado em seus produtos. Por outro lado, as estruturas produtivas baseadas, majoritariamente, na produção de bens intensivos em recursos naturais apresentam baixa complexidade, que se traduz em baixo dinamismo e retorno para a economia.

As Cadeias Globais de Valor (CGV) fornecem a participação de um determinado país ao longo da cadeia de valor, que perpassa etapas como Pesquisa \& Desenvolvimento à Marketing. De outro modo, "a noção de CGV em geral está associada à cadeia de fornecedores, e aos processos de fragmentação, especialização vertical, produção em multi-estágios, subcontratação, realocação, offshoring, comércio de tarefas" (REIS \& ALMEIDA, 2014, p. 4).

A economia brasileira, sob o processo intensivo de industrialização (1930-1980), viu sua renda nacional crescer em torno de 500\%. No paradigma metalomecânico-químico, a economia nacional buscou o emparelhamento tecnológico, que contribuiu para que a participação da indústria de transformação no PIB se elevasse de maneira acentuada. Com o processo de reestruturação produtiva, iniciada em meados dos anos 1980, a globalização e a emergência do paradigma microeletrônico, a economia brasileira passa a perder dinâmica industrial (AREND \& FONSECA, 2012).

Nas Cadeias Globais de Valor (CGV), a economia brasileira encontra-se com maior participação em setores cuja característica projeta-se como intensivos em recursos naturais, mais especificamente, em produtos minerais e agrícolas. Sobretudo, vale destacar a participação de produtos químicos em suas reexportações, no qual compreende seu consumo, majoritariamente, para a produção de commodities agrícolas (OCDE/OMC, 2013; REIS \& SOUZA, 2015).

A inserção estratégica nas cadeias globais de valor, para além de ganhos de mercados em setores competitivos, sobretudo agrícolas e minerais, deve ocorrer em grupos de bens de maior valor agregado e possibilidade de espraiamento dinâmico na estrutura produtiva interna (RODRIK, 2005).

O objetivo do artigo é constatar como a economia brasileira se inseriu, globalmente, a partir da mudança de paradigma tecnológico iniciado algumas décadas atrás. Percebe-se que, após a mudança de paradigma, a economia brasileira passa por um processo de perda de dinamismo industrial e aumento da pauta exportadora de bens intensivos de recursos naturais, menos complexos.

O artigo está dividido em três partes, além da introdução e considerações finais. Em um primeiro momento, discorre-se sobre o aporte teórico estruturalista, que relaciona a inserção comercial internacional e dinâmica produtiva interna. Em seguida, expõe-se um breve panorama histórico da economia brasileira, de seu processo de industrialização e dinâmica sob o paradigma metalomecânico-químico à mudança estrutural de fins do século XX. Por último, será analisada a inserção do Brasil nas CGV's, sua participação nos indicadores e os setores que possuem maior 
relevância para compreender a posição nacional no mercado internacional, bem como sua complexidade produtiva.

\section{A ECONOMIA BRASILEIRA DO PARADIGMA FORDISTA À REESTRUTURAÇÃO PRODUTIVA}

Do período colonial brasileiro ao início do século XX, a estrutura econômica brasileira constituiu-se basicamente da exploração e exportação do setor primário, com ênfase no café, borracha e cana-de-açúcar. Pouco dinâmica, a economia do país apenas dobrou de tamanho durante todo o século XIX, em contraponto a uma elevação próxima a 500\% no século seguinte (FONSECA, 1989; AREND; SINGH; BICHARRA, 2016).

Com a crise do final dos anos 1920 e seus efeitos na economia brasileira, o Estado passou a agir em defesa da indústria cafeeira. Posteriormente, durante o período de 1930-1950, o Estado brasileiro passou a financiar e investir diretamente no desenvolvimento da indústria nacional. Mais especificamente, em setores de insumos básicos como mineração, siderurgia, petroquímica, etc. e em setores de infraestrutura como o energético e de transportes (VERSIANI; SUZIGAN, 1990).

Conforme Arend (2009), a partir da década de 1950, durante o governo Juscelino Kubitschek, uma nova etapa do processo de industrialização brasileira emerge. Diferentemente da estratégia nacional desenvolvimentista anterior, o período passa a ter uma profunda influência do capital internacional. Durante esse período, a constituição da indústria brasileira passa a ter investimentos consideráveis do exterior, com ênfase investimento estrangeiro direto (IED) e fruto das políticas estabelecidas pelo Plano de Metas (1956-1961).

Deve-se destacar que durante esse período o paradigma tecnológico vigente caracterizava-se pela ênfase nos complexos metalomecânicos, aliado aos gêneros petroquímicos que estavam em pleno desenvolvimento. Ou seja, vigorava o paradigma fordista de produção industrial tanto nas economias desenvolvidas como também nas periféricas, que buscavam o emparelhamento tecnológico devido o ingresso tardio no capitalismo moderno.

De outro modo, pode-se argumentar que a atuação "dos gêneros industriais constituintes dos complexos metal-mecânico-químico apresentou aumento significativo no valor da transformação industrial a partir da consolidação do Plano de Metas, passando de $25 \%$, em 1939, para $43 \%$ em 1959". O que se observa nesse período é que houve um emparelhamento tecnológico no Brasil para com o paradigma tecnológico predominante. "A continuidade da mudança estrutural deu-se até 1980, pois os gêneros industriais constituintes dos complexos metalmecânico-químico representavam 58\% do valor da transformação industrial da indústria de transformação" (AREND; SINGH; BICHARRA, 2016, p. 4).

A mudança da estrutura produtiva nacional para uma base de indústria pesada e, especialmente, caracterizada pela injeção maciça de investimento estrangeiro aliado a inserção das multinacionais na produção doméstica, traz consigo uma realidade onde as empresas internacionais passam a dominar a produção de bens industriais dentro do mercado nacional. Como aponta Serra (1982), as empresas multinacionais predominavam na produção de bens de consumo duráveis e

Estudos do CEPE [ISSN 1982-6729]. Santa Cruz do Sul, n. 46, p. 22-38, jul./dez. 2017. https://online.unisc.br/seer/index.php/cepe/index 
participavam em $85 \%$ das vendas em 1970. Na mesma medida, a produção de bens de capital era produzida majoritariamente por empresas estrangeiras e detinham uma parcela de $57 \%$ das vendas.

A partir da década de 1970, sobretudo, sob o impacto da crise do petróleo na economia brasileira, o Estado passa a intervir cada vez mais nos rumos do desenvolvimento industrial, a fim contornar a crise:

\begin{abstract}
Após o choque do petróleo e a elevação dos preços das matérias-primas no mercado internacional (1973-74), o Estado aumentou ainda mais sua influência sobre os rumos do desenvolvimento industrial. Embora a política macroeconômica tivesse sido mantida moderadamente expansionista, à custa de maior endividamento externo, o ritmo de crescimento da produção industrial e os níveis de consumo caíram na segunda metade dos anos setenta. O déficit da balança comercial fez com que fossem mantidos e ampliados os incentivos e subsídios à exportação de manufaturados, e aumentadas as barreiras nãotarifárias às importações. Entretanto, os níveis de investimento no setor industrial permaneceram elevados, o que se deve à ação estruturadora do Estado sobre o setor industrial na segunda metade dos anos setenta, de forma semelhante ao que ocorrera na década de cinquenta (VERSIANI; SUZIGAN, 1990, p. 20).
\end{abstract}

Ainda em conformidade com Versiani e Suzigan (1990), compreende-se que o Estado brasileiro se propõe a uma estratégia de continuada fase de investimentos para que pudesse completar seu ciclo de industrialização, pela adoção do II Plano Nacional de Desenvolvimento (II PND), entre 1975 e 1979, na reconhecida "marcha forçada". Para tanto, utilizou-se de investimentos em áreas que vão desde insumos até bens de capital.

Sob o paradigma fordista, verificou-se uma mudança na estrutura industrial brasileira, com crescentes ganhos de produtividade e um crescimento econômico considerável durante quatro décadas seguidas. Nesse período, a economia nacional funcionou de forma satisfatória. O período do milagre econômico entre o final da década de 1960 e início dos anos 1970, só foi possível graças aos intensos investimentos estrangeiros e a estabilizada tecnológica do paradigma metalomecânico e petroquímico.

A partir da década de 1980, verifica-se a insuficiência e declínio do paradigma metalomecânico-químico, característico do fordismo e a emergência do paradigma microeletrônica, com vistas a contornar as crises vigentes do capitalismo. A reestruturação produtiva global coincide com a abertura comercial brasileira, o que implica em uma mudança estrutural com perda de dinamicidade e consequente estagnação econômica. A reestruturação produtiva global anuncia a necessidade dos países periféricos em buscar alternativas para não perder os ganhos da estrutura industrial do paradigma anterior (AREND; FONSECA, 2012).

Laplane (1992) indica que a dinâmica da industrial no âmbito global não mais se caracteriza pelo seu centro em atividades industriais onde predominava o setor produtivo automobilístico que, por sua vez, era característico do paradigma fordista. Surge o novo paradigma tecnológico baseado na microeletrônica.

Ao longo da década de 1980 e 1990, a estrutura produtiva brasileira evoluiu de forma heterogenia em comparação com o restante dos países que adentraram e se adaptaram ao novo paradigma microeletrônico. Os setores da indústria nacional mais dinâmicos mantiveram um movimento de grande estagnação (CASSIOLATO, 2001). "O setor de material elétrico, eletrônico e de comunicações, que representava $7,12 \%$ da indústria de transformação em 1980, passa a representar apenas 6,56\% em 1999". Esse decréscimo representa um atraso da economia nacional "em direção a

Estudos do CEPE [ISSN 1982-6729]. Santa Cruz do Sul, n. 46, p. 22-38, jul./dez. 2017. https://online.unisc.br/seer/index.php/cepe/index 
setores típicos do paradigma microeletrônico" que "é seguido por um aumento significativo da participação das indústrias processadoras de recursos naturais no produto total da indústria" (AREND \& FONSECA, 2012, p. 43).

Hidalgo e Feistel (2013) apontam que as exportações brasileiras durante as décadas de 1990 e 2010 foram predominantemente produtos intensivos em recursos naturais. Podem-se distinguir dois períodos distintos, com aumento de produtos intensivos de capital durante a década de 1990, e perda de participação de produtos intensivos em capital e retomada de intensivos primários como principal da pauta externa brasileira, a partir de 2001.

Durante o processo de industrialização pesada no Brasil, os investimentos estrangeiros eram direcionados em larga medida para o setor produtivo industrial. A partir do final da década de 1980 os ingressos de capitais externos, em forma de investimento estrangeiro direto (IED), passaram a declinar nesse setor. A abertura econômica, iniciada nos anos 1990, serviu de estímulo para a entrada abrupta de capital internacional. Entretanto, esses investimentos foram direcionados para o setor especulativo e de serviços, ao invés do setor industrial (AREND \& FONSECA, 2012).

A estratégia delineada nos anos 1990, com a liberalização da economia, não surtiu o efeito esperado na indústria. O investimento estrangeiro direto (IED) que entrou no país foi muito débil nos setores onde o paradigma microeletrônico se alicerçou. "Assim, os setores dinâmicos do paradigma de crescimento mundial não se difundiram para o Brasil na forma de investimentos estrangeiros diretos como no passado". Além do mais, os investimentos permaneceram direcionados para os setores onde ainda vigoravam o paradigma metalomecânico-químico. Ou seja, "o padrão de investimento direto externo, no período 1980-1995, e a extrema dependência por transferências tecnológicas, característica da estratégia de desenvolvimento do período anterior a 1980", obteve profunda ação no processo de "debilidade do processo de mudança industrial no período posterior" (AREND \& FONSECA, 2012, p. 46).

Conforme mostra o gráfico 1, a entrada de IED de 1980 a 1995 dirige-se essencialmente para os setores intensivos em recursos naturais e setores cuja dinâmica está ancorada no paradigma metalomecânico-químico, que na concepção neoschumpeteriana diz respeito a quarta revolução tecnológica.

Estudos do CEPE [ISSN 1982-6729]. Santa Cruz do Sul, n. 46, p. 22-38, jul./dez. 2017. https://online.unisc.br/seer/index.php/cepe/index 
Gráfico 1 - Forma de Entrada dos IEDs segundo o Setor Tecnológico no Período 1980-1995, em Percentual do Total para a Indústria

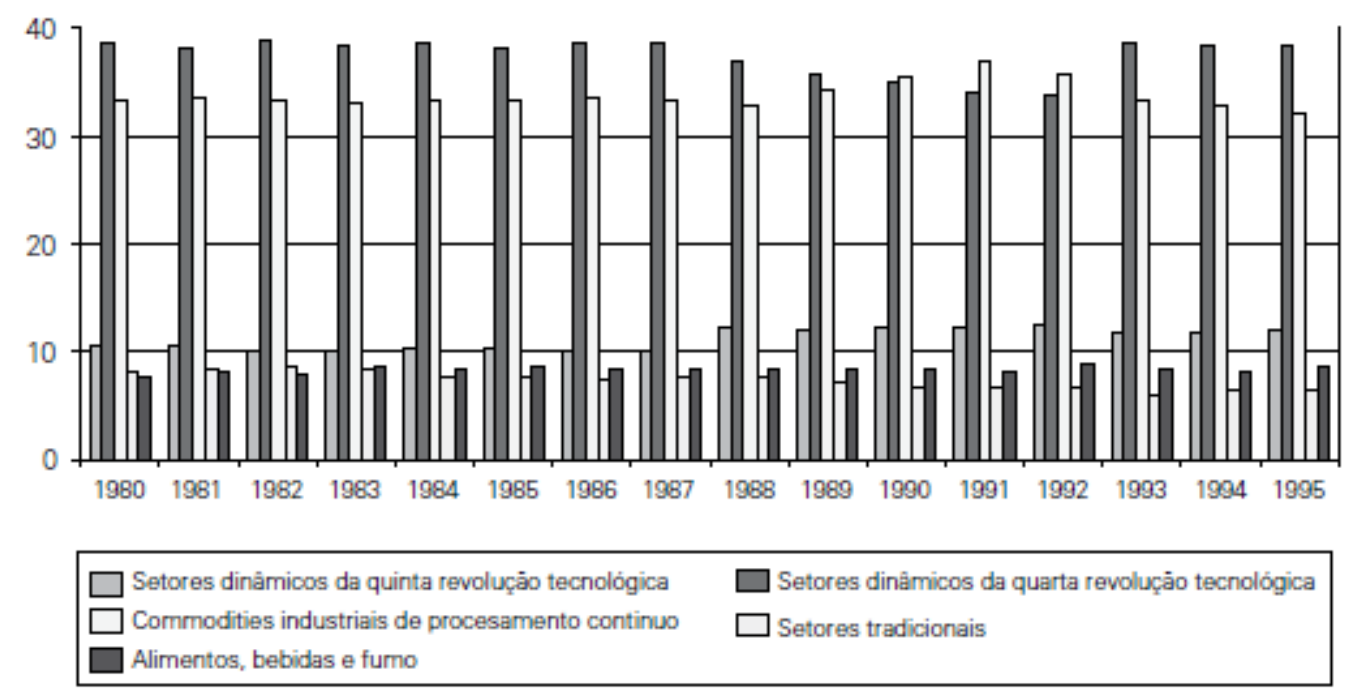

Fonte: Arend \& Fonseca (2012).

Além disso, como exposto anteriormente, a participação da indústria de transformação na economia brasileira tem se demonstrado diminuta a cada ano. Isso se verifica na queda em $37 \%$ da participação brasileira na manufatura global entre 1980 a 2010. Por um lado, os países desenvolvidos apresentam o processo de industrialização devido à mudança estrutural das economias para setores intensivos em tecnologia e ganhos consideráveis de produtividade. Para o Brasil, por outro lado, isso decorre de forma precoce, em virtude da reestruturação produtiva global (AREND; SINGH; BICHARRA, 2016).

Se comparado com países como China, Malásia, Coreia do Sul e Tailândia, podemos identificar que o Brasil possuía, em 1970, 10\% a mais do tamanho da indústria de transformação, em comparação ao somatório das indústrias desses países. Em 1980, a indústria nacional ainda equivalia ao somatório dos quatro países. Entretanto, conforme o gráfico 2, no ano de 2010, a indústria brasileira representou apenas $7 \%$ do tamanho da indústria de transformação dos países analisados. Isso representa a forma intensiva que esses países se industrializaram e a perda da dinâmica industrial brasileira. 
Gráfico 2 - Percentual do Valor Adicionado da Indústria de Transformação do Brasil em relação ao somatório de China, Malásia, Coreia do Sul e Tailândia, em US\$ de 2005

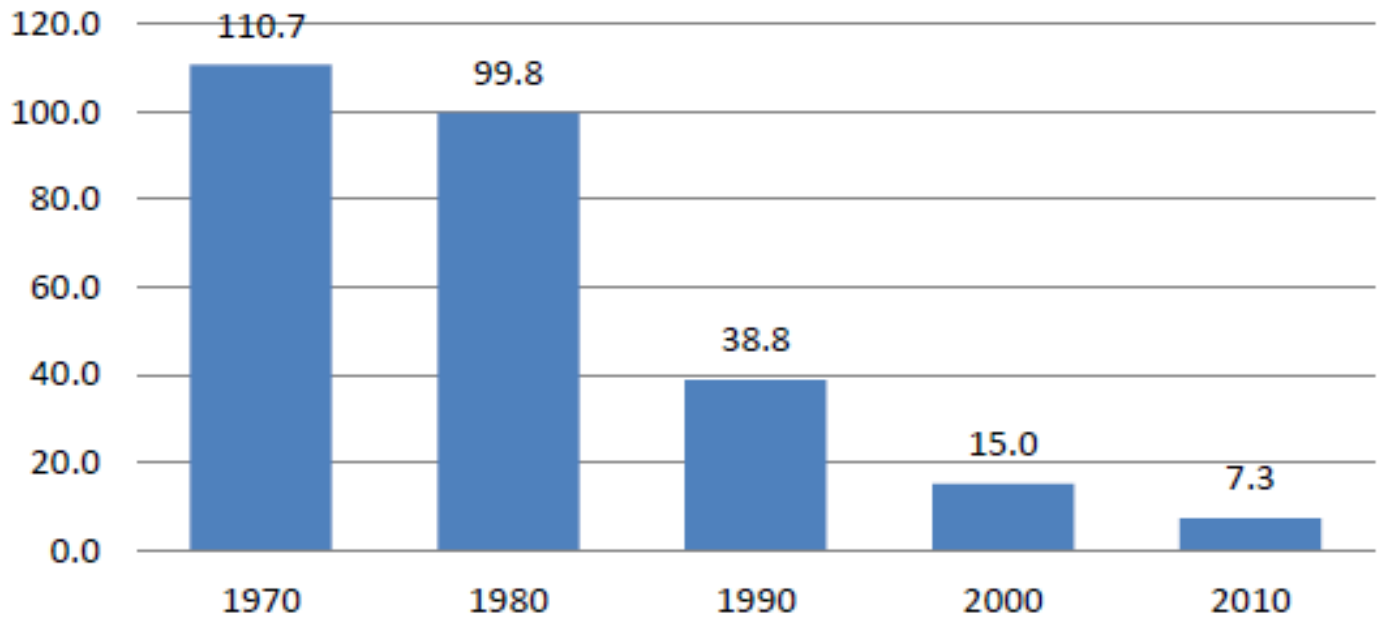

Fonte: Arend; Singh; Bicharra (2016).

Essas evidências direcionam o Brasil para uma posição produtiva dentro do processo de globalização que se especializa, em larga medida, no setor primário, intensivo em recursos naturais. Dada à reestruturação produtiva global, a perda da dinâmica industrial nacional caracteriza-se pela reprimarização da economia dentro da nova estrutura produtiva mundial. O processo de globalização traz consigo o fenômeno de cadeias globais de produção, onde, dentro da nova dinâmica internacional, a produção tende a se descentralizar e ter seus pontos de especialização espalhados geograficamente pelo globo.

\section{A INSERÇÃO DO BRASIL NAS CADEIAS GLOBAIS DE VALOR (CGV)}

Dada a reestruturação produtiva mundial e a nova dinâmica de produção dentro da globalização, os processos produtivos tendem a se ramificar ao longo de uma cadeia de valor que perpassa o processo de produção até o consumo final. Uma cadeia de valor nos mostra todas as empresas, indivíduos e nações que participam da produção de bens e serviços na economia. Essa concepção envolve tanto as ocupações com o desenvolvido de um novo produto, passando pela sua produção, distribuição e marketing, até seu consumo final (OCDE; OMC, 2013).

Uma Cadeia Global de Valor (CGV) representa às cadeias de valor que estão vinculadas a economia mundializada. Ou seja, significa a "dispersão das cadeias de valor pelo mundo, seja através da distribuição de estágios de produção de uma firma entre diversos países ou a terceirização de parte da cadeia de valor desta firma para parceiros externos". De outro modo, "a noção de CGV em geral está associada à cadeia de fornecedores, e aos processos de fragmentação, especialização vertical, produção em multi-estágios, subcontratação, realocação, offshoring, comércio de tarefas" (REIS \& ALMEIDA, 2014, p. 4). 
As CGV não se caracterizam como sendo um fenômeno muito recente nos estudos econômicos. Elas se compreendem como tal a partir da internacionalização do processo produtivo com o advento da globalização, como afirmam Reis \& Almeida (2014, p. 4):

\begin{abstract}
$\mathrm{Na}$ verdade, as CGV não são um fenômeno novo e acompanham a globalização desde o princípio; novas são a maior velocidade e complexidade de suas atividades, em termos geográficos, setoriais e funcionais. Nesse processo, aumentam os fluxos de Investimento Estrangeiro Direto (IED), novas regiões estão se inserindo nos mercados internacionais e os serviços (principalmente os relacionados diretamente às indústrias de transformação) estão ganhando maior importância relativa no comércio mundial.
\end{abstract}

Segundo o relatório da OCDE/OMC (2013), esse fenômeno está intrinsecamente associado ao processo de mutação no terreno dos negócios corporativos e a internacionalização do capital. A reestruturação produtiva está ancorada na diminuição dos custos comerciais e a inserção de novas tecnologias produtivas e de transportes. Essencialmente, isso serve para redução de custos e ganhos em eficiência produtiva.

Podemos compreender a posição dentro das CGVs através da quantidade de valor adicionado dentro das diversas atividades do processo produtivo. Nessa avaliação, podemos identificar, no gráfico 3 , a posição do país no processo que perpassa a Pesquisa \& Desenvolvimento (P\&D) até o marketing e serviços dentro da cadeia de valor.

\title{
Gráfico 3 - A curva sorriso: valor adicionado ao longo da CGV
}

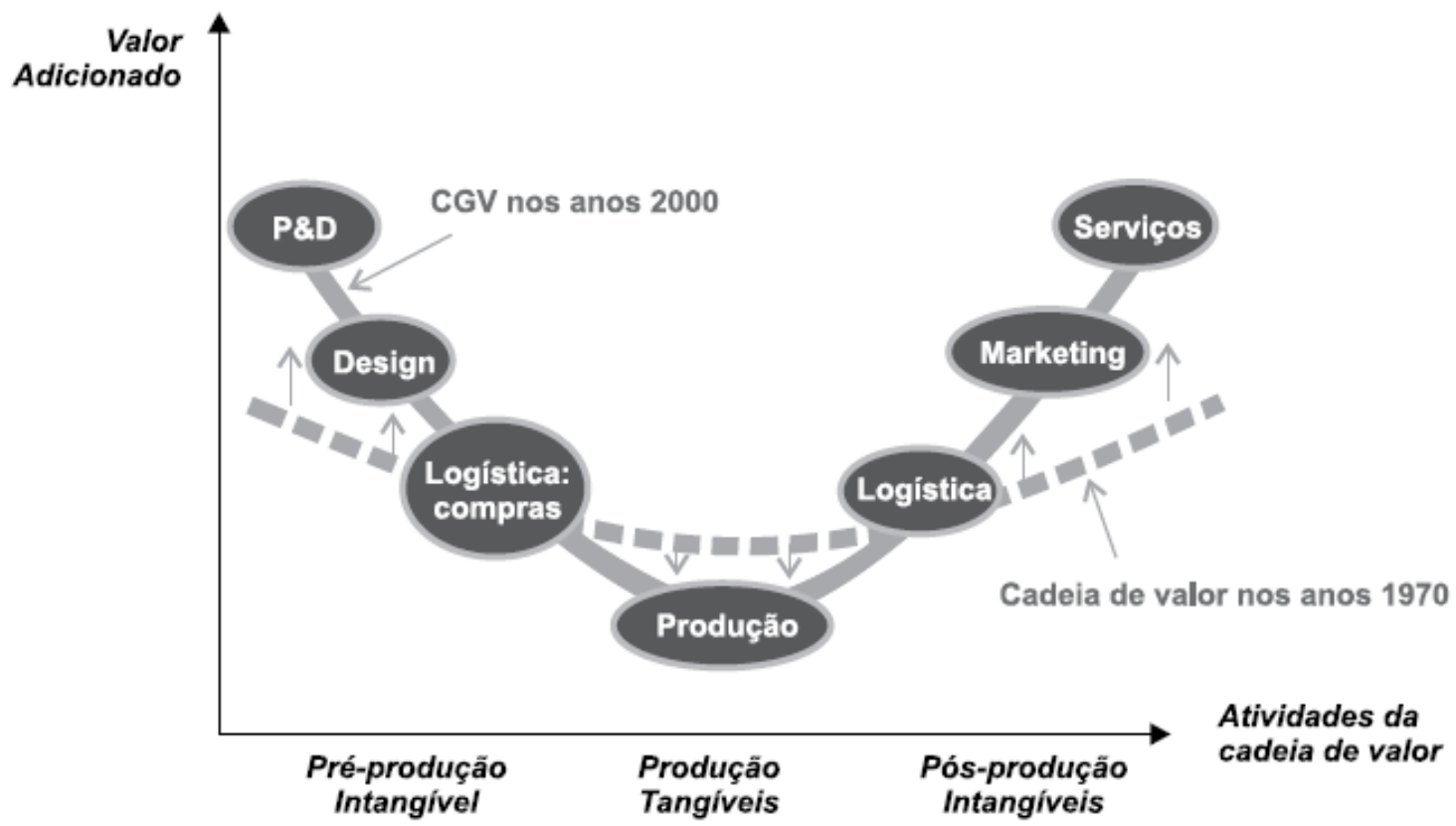

Fonte: Reis \& Souza (2015).

Dentro do relatório, podemos identificar dois indicadores que são fundamentais para compreender a participação das nações dentro das Cadeias Globais de Valor (CGV). O primeiro deles diz respeito à quantidade de insumos estrangeiros inseridos nas exportações do país, ou seja, a quantidade de insumos de outros países incorporados nos produtos exportados do país. Esse

Estudos do CEPE [ISSN 1982-6729]. Santa Cruz do Sul, n. 46, p. 22-38, jul./dez. 2017. https://online.unisc.br/seer/index.php/cepe/index 
indicador caracteriza-se como um indicador para trás dentro da cadeia de produção. O segundo refere-se à quantidade de insumos que são produzidos no país que estão inseridos nas exportações dos demais países. É dizer, a parcela dos insumos, por exemplo, do Brasil, incorporado nas exportações dos demais países. Esse é um indicador para frente da CGV. A soma percentual dos dois indicadores representa a participação nas CGVs (OCDE/OMC, 2013).

Países, cuja pauta de exportação é marcada, em larga escala, por produtos intensivos em recursos naturais, como o Brasil, apresentam baixo conteúdo estrangeiro em sua exportação. Entretanto, nações com maior grau de diversificação industrial podem apresentar o mesmo aspecto, tais como os EUA e Japão. Conforme o gráfico 4 nos mostra, o Brasil apresenta baixa participação do valor adicionado importado nas exportações, menos de 10\%. Por outro lado, os países com grande inserção nas CGVs apresentam maior porcentagem de conteúdo importado em suas exportações, como a China.

\section{Gráfico 4 - Participação do valor adicionado importado nas exportações (\%) de um grupo selecionado de países}

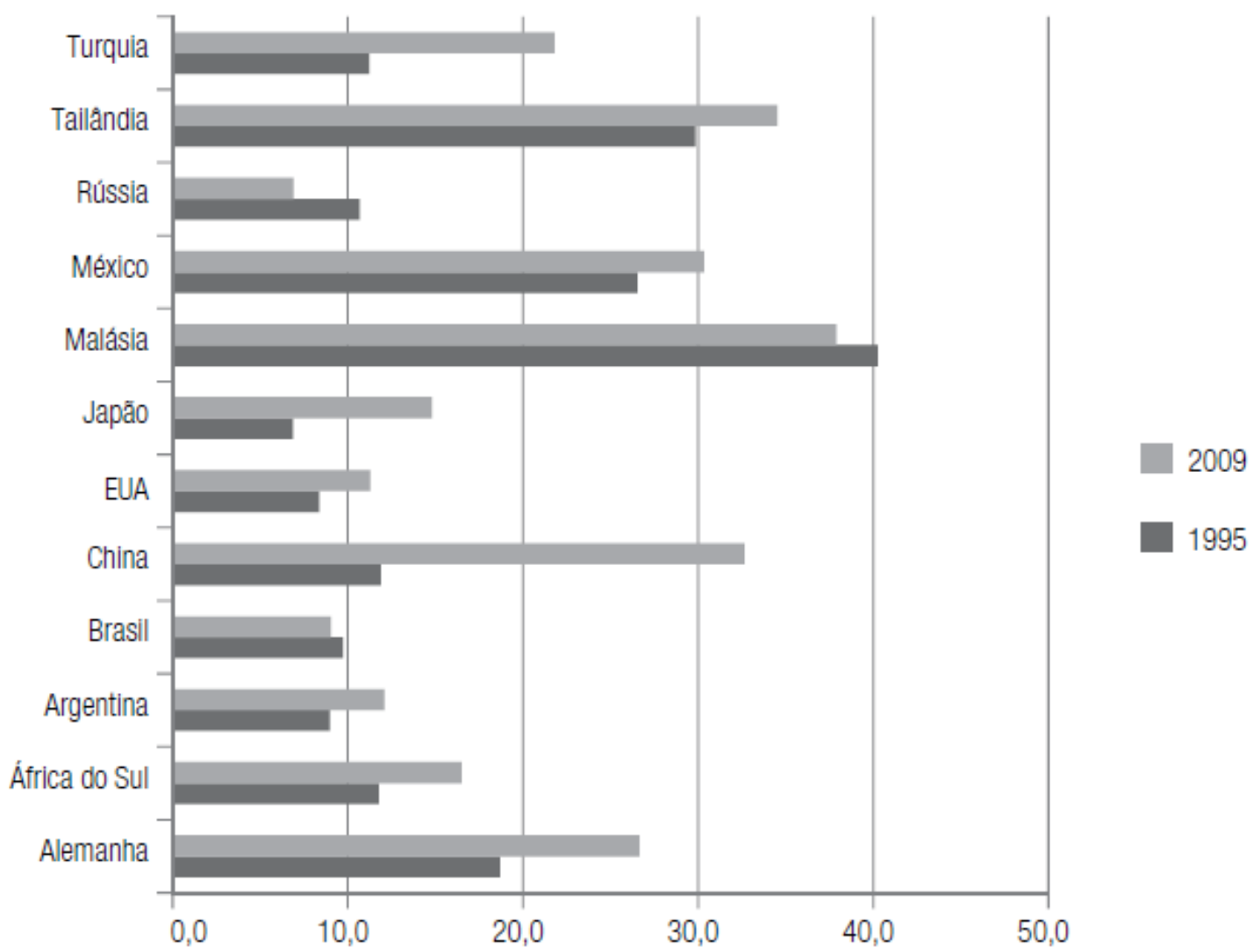

Fonte: Reis \& Souza (2015).

Por outro lado, o indicador para frente, referente à participação nas exportações das demais economias, apresenta maior participação para a economia brasileira. O Brasil apresenta uma participação do valor adicionado doméstico exportado nas exportações do restante do mundo de, aproximadamente, $27 \%$. Isso se apresenta devido à economia nacional estar baseada, em larga

Estudos do CEPE [ISSN 1982-6729]. Santa Cruz do Sul, n. 46, p. 22-38, jul./dez. 2017. https://online.unisc.br/seer/index.php/cepe/index 
medida, na exportação de bens intensivos de recursos naturais, cuja similaridade pode ser encontrada em países como Rússia, conforme o gráfico 5 demonstra.

Gráfico 5 - Participação do valor adicionado doméstico exportado nas exportações (\%) do restante do mundo

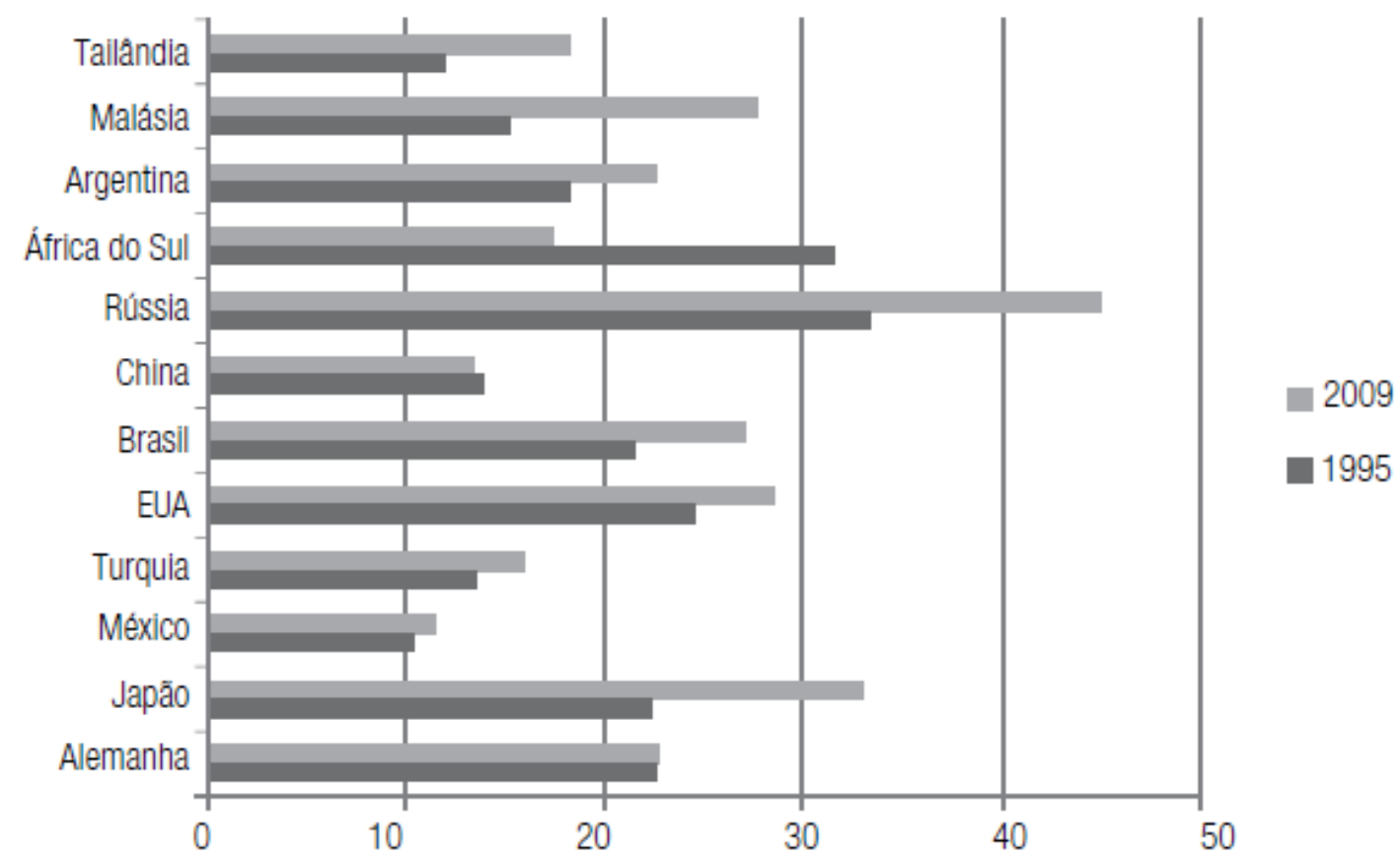

Fonte: Reis \& Souza (2015).

Ao somar a porcentagem, tanto do indicador para frente como também o indicador para trás, podemos identificar que o Brasil possui participação nas cadeias globais de valor de, aproximadamente, 37\%. Esse valor é simular aos números encontrados no EUA, onde a participação nas CGVs alcança, aproximadamente, 40\%. Entretanto, esse valor preliminar não nos capacita a compreender em quais setores estão os altos indicadores para frente ou para trás.

Analisando a tabela 1 identificamos que a participação do valor adicionado importado nas exportações por setor, ou seja, a quantidade de insumos importados incorporados nas exportações brasileiras mantém-se constantes, com destaque para o setor de produtos químicos. Isso se evidencia, em larga medida, pelo uso de pesticidas e herbicidas nas monoculturas nacionais, que são uma parcela grande das exportações brasileiras.

Tabela 1 - Participação do valor adicionado importado nas exportações por setor (\%)

\begin{tabular}{|c|c|c|c|c|c|c|c|c|c|}
\hline País & $\begin{array}{l}\text { Total } \\
2009\end{array}$ & $\begin{array}{c}\text { Agricultura } \\
\text { Floresta, } \\
\text { Caça e } \\
\text { pesca }\end{array}$ & $\begin{array}{c}\text { Minera } \\
\text { ção } \\
\text { e } \\
\text { extraçã } \\
\text { o }\end{array}$ & $\begin{array}{c}\text { Alimentos, } \\
\text { Bebidas e } \\
\text { tabaco }\end{array}$ & $\begin{array}{l}\text { Têxteis, } \\
\text { Couro e } \\
\text { calçados }\end{array}$ & $\begin{array}{l}\text { Químicos } \\
\text { E prod. } \\
\text { Minerais } \\
\text { Não } \\
\text { metal }\end{array}$ & $\begin{array}{l}\text { Máquinas } \\
\text { e equip. }\end{array}$ & $\begin{array}{l}\text { Equip. } \\
\text { Elétricos } \\
\text { e óticos }\end{array}$ & $\begin{array}{l}\text { Equip. de } \\
\text { transporte }\end{array}$ \\
\hline Alemanha & 26,6 & 0,1 & 0,0 & 0,8 & 0,3 & 6,1 & 3,8 & 2,5 & 6,1 \\
\hline África do Sul & 16,5 & 0,7 & 3,9 & 0,6 & 0,2 & 2,0 & 0,0 & 0,3 & 2,5 \\
\hline
\end{tabular}

Estudos do CEPE [ISSN 1982-6729]. Santa Cruz do Sul, n. 46, p. 22-38, jul./dez. 2017. https://online.unisc.br/seer/index.php/cepe/index 


\begin{tabular}{|c|c|c|c|c|c|c|c|c|c|}
\hline Argentina & 12,1 & 0,7 & 0,2 & 2,3 & 0,9 & 2,0 & 0,3 & 0,4 & 2,9 \\
\hline China & 32,6 & 0,0 & 0,2 & 0,5 & 3,3 & 4,2 & 2,9 & 14,3 & 1,3 \\
\hline EUA & 11,3 & 0,4 & 0,1 & 0,5 & 0,2 & 3,3 & 0,9 & 1,5 & 1,7 \\
\hline Japão & 14,8 & 0,0 & 0,0 & 0,1 & 0,1 & 2,8 & 1,2 & 4,3 & 3,1 \\
\hline México & 30,3 & 0,3 & 0,6 & 0,6 & 0,7 & 1,8 & 1,0 & 14,8 & 6,6 \\
\hline Rússia & 6,9 & 0,2 & 1,9 & 0,1 & 0,0 & 1,2 & 0,5 & 0,2 & 0,3 \\
\hline Tailândia & 34,5 & 0,2 & 0,1 & 1,9 & 2,5 & 3,7 & 0,8 & 17,2 & 1,5 \\
\hline Turquia & 21,8 & 0,3 & 0,1 & 0,6 & 2,7 & 3,7 & 1,5 & 1,3 & 3,6 \\
\hline
\end{tabular}

Fonte: Reis \& Souza (2015).

Em referência ao indicador para frente, ou seja, a participação do valor adicionado doméstico exportado nas exportações por setor, podemos perceber que no caso brasileiro a maior contribuição se dá através de setores intensivos em recursos naturais, tais como agricultura e mineração, onde a participação alcança 4,1 e 3,7\%, respectivamente. Isso também se verifica em países, cuja estrutura produtiva é similar, tais como Rússia e África do Sul.

Tabela 2 - Participação do valor adicionado doméstico exportado nas exportações (\%) do restante do mundo, por setor

\begin{tabular}{|c|c|c|c|c|c|c|c|c|c|c|c|}
\hline País & $\begin{array}{l}\text { Total } \\
2009\end{array}$ & $\begin{array}{c}\text { Agricultu- } \\
\text { ra } \\
\text { Floresta, } \\
\text { Caça e } \\
\text { pesca }\end{array}$ & $\begin{array}{c}\text { Minera- } \\
\text { ção e } \\
\text { extraçã } \\
0\end{array}$ & $\begin{array}{c}\text { Alimentos, } \\
\text { Bebidas e } \\
\text { tabaco }\end{array}$ & $\begin{array}{c}\text { Têxteis, } \\
\text { Couro } \\
e \\
\text { calçado } \\
\text { s }\end{array}$ & $\begin{array}{l}\text { Químicos } \\
\text { E prod. } \\
\text { Minerais } \\
\text { Não metal }\end{array}$ & $\begin{array}{l}\text { Máqui- } \\
\text { nas } \\
\text { e } \\
\text { equip. }\end{array}$ & $\begin{array}{l}\text { Equip. } \\
\text { Elétricos } \\
\text { e óticos }\end{array}$ & $\begin{array}{l}\text { Varejo } \\
\text { atacado, } \\
\text { rest. E } \\
\text { hotéis }\end{array}$ & $\begin{array}{l}\text { Interm. } \\
\text { Financ }\end{array}$ & $\begin{array}{c}\text { Serviços } \\
\text { de } \\
\text { negócios }\end{array}$ \\
\hline Alemanha & 22,8 & 0,2 & 0,2 & 0,1 & 0,1 & 2,7 & 1,8 & 1,5 & 2,2 & 0,8 & 5,2 \\
\hline África do Sul & 1,3 & 0,1 & 7,8 & 0,1 & 0,1 & 0,4 & 0,0 & 0,2 & 1,1 & 0,8 & 0,9 \\
\hline Argentina & 22,5 & 3,7 & 2,6 & 2,0 & 1,5 & 2,1 & 0,3 & 0,2 & 1,7 & 0,5 & 1,2 \\
\hline Brasil & 27,2 & 4,1 & 3,7 & 0,9 & 0,5 & 2,5 & 0,4 & 0,3 & 3,4 & 0,8 & 2,0 \\
\hline China & 13,4 & 0,7 & 0,6 & 0,2 & 0,5 & 1,6 & 0,5 & 2,7 & 1,8 & 0,6 & 0,7 \\
\hline
\end{tabular}




\begin{tabular}{|c|c|c|c|c|c|c|c|c|c|c|c|}
\hline EUA & 28,5 & 0,5 & 0,9 & 0,1 & 0,2 & 0,4 & 0,9 & 3,2 & 2,8 & 2,1 & 6,8 \\
\hline Japão & 33,0 & 0,1 & 0,0 & 0,2 & 0,3 & 4,1 & 1,2 & 4,7 & 4,1 & 1,6 & 3,1 \\
\hline Malásia & 27,7 & 1,73 & 4,3 & 0,3 & 0,1 & 2,7 & 0,8 & 7,4 & 4,0 & 1,7 & 1,1 \\
\hline México & 11,5 & 0,2 & 3,6 & 0,1 & 0,1 & 0,8 & 0,1 & 0,8 & 1,9 & 0,4 & 0,7 \\
\hline Rússia & 44,9 & 0,8 & 17,5 & 0,1 & 0,1 & 5,7 & 0,9 & 0,4 & 5,5 & 0,5 & 1,8 \\
\hline Tailândia & 18,3 & 1,0 & 0,5 & 0,3 & 0,9 & 2,9 & 0,2 & 5,3 & 2,5 & 0,2 & 0,3 \\
\hline Turquia & 15,9 & 0,5 & 0,8 & 0,1 & 1,5 & 1,5 & 0,4 & 0,2 & 2,4 & 0,7 & 1,1 \\
\hline
\end{tabular}

Fonte: Reis \& Souza (2015).

Em linhas gerais, a contribuição brasileira dentro das cadeias globais de valor tem se caracterizado pelo fornecimento de bens intensos em recursos naturais, com baixa produtividade e intensivos em mão de obra. O país tem se demonstrado um fornecedor de matérias primas e alimentos para o mundo, estando distante da produção manufatureira com alto valor agregado. Dado o processo de perda da dinâmica industrial nacional a partir dos anos 1980, em decorrência da reestruturação produtiva global, o Brasil viu perdas significativas na indústria e aumento relativo de setores primários na pauta produtiva.

Nas cadeias globais de valor, o país é pobre no desenvolvimento de etapas anteriores a produção, como P\&D e Design. Isso também se verifica em etapas posteriores à produção, como no caso do Marketing e o oferecimento de serviços. A posição brasileira nas cadeias globais de valor reside, como mostram os dados, em setores de produção tangível, com baixo valor adicionado (bens primários).

O Gráfico 6 expressa a evolução da taxa de cobertura² do comércio brasileiro, segmentado por intensidade tecnológica, conforme delimitação da Nomenclatura Comum do Mercosul. Nesta perspectiva, apreende-se em plano amplo a evolução setorial da inserção externa brasileira nas cadeias globais de valor, como explicitado nos gráficos anteriores.

\footnotetext{
${ }^{2}$ A taxa de cobertura indica saldo comercial relativo de dado grupo de bens sobre o comércio de um país. Se for superior a 1 , verifica-se que há influência sobre o superávit comercial se apresentar e tende a provocar déficit se for inferior a 1 . Compreende-se que a magnitude do segmento sobre o superávit comercial do país é dado por quanto maior for o índice que 1.
}

Estudos do CEPE [ISSN 1982-6729]. Santa Cruz do Sul, n. 46, p. 22-38, jul./dez. 2017. https://online.unisc.br/seer/index.php/cepe/index 
Gráfico 6 - Evolução da taxa de cobertura do comércio brasileiro por intensidade tecnológica $(1970-2010)(\%)$

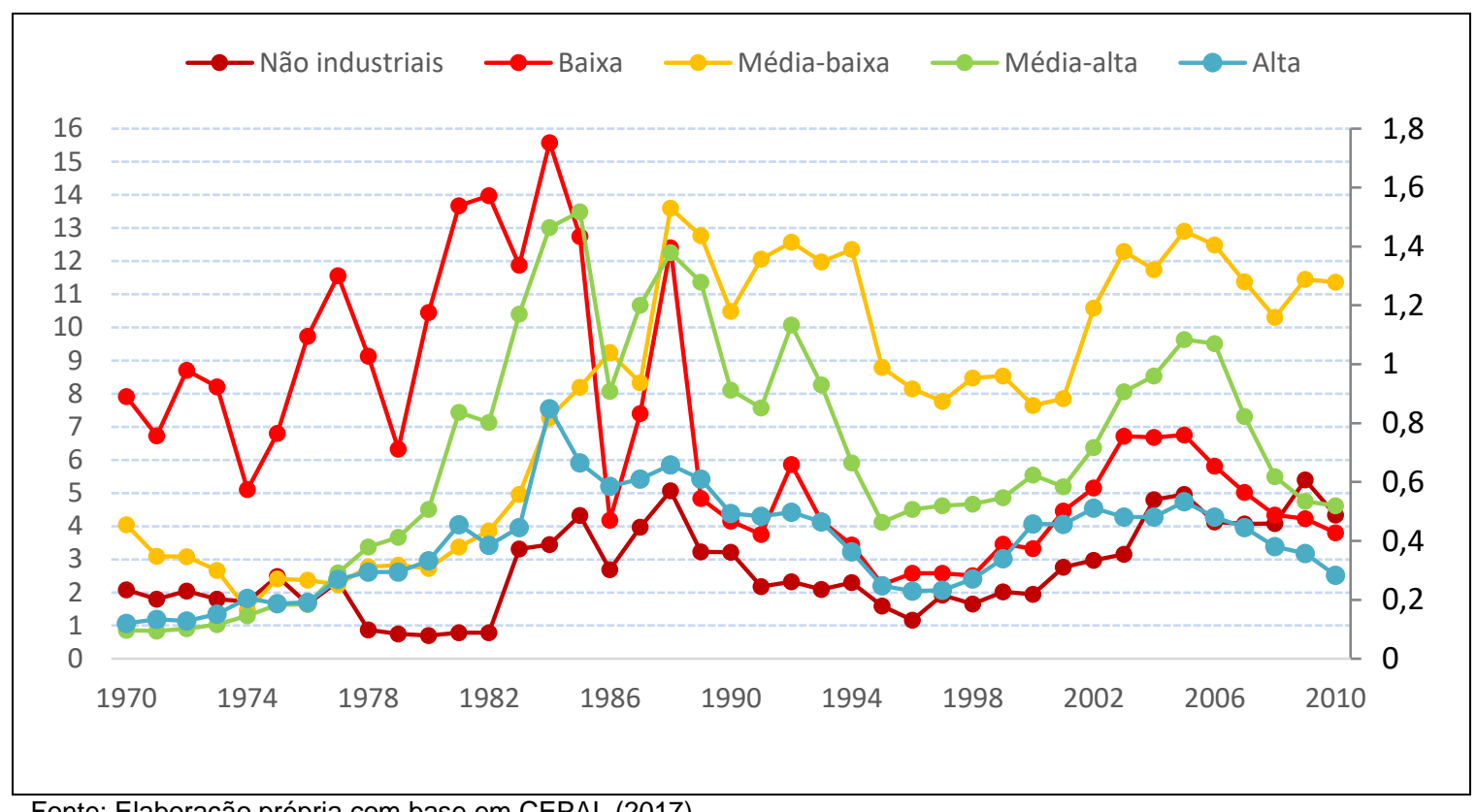

Fonte: Elaboração própria com base em CEPAL (2017).

É verificado que há significativa maior influência de setores de baixa intensidade tecnológica e de bens não industriais sobre as exportações brasileiras, em comparação a suas respectivas importações, ao longo de toda a série. Estas informações revelam a posição brasileira de abastecedor do mercado mundial em bens de baixo valor agregado.

Por sua vez, enfoca-se sobre os bens oriundos da indústria de transformação e observa-se a tendência de taxa de cobertura inferior a 1, com algumas poucas exceções ${ }^{3}$. Disso, compreende-se que o Brasil é franco importador de bens de maior valor agregado, com destaque para setores de alta intensidade tecnológica, o que reflete a fragilidade estrutural do país e a baixa competitividade global.

O Grafo 1 revela a evolução do product space brasileiro entre 1970 e 2010, indicando a complexidade das exportações do Brasil no período. Os grafos representam o espraiamento tecnológico, resultante da interação entre setores de maior intensidade tecnológica no mercado produtivo interno em função da especialização das exportações.

Os grafos são compostos por pontos e vértices. Cada ponto representa um setor produtivo e cada vértice à ligação entre estes em função de seu grau de integração na produção. Quanto mais ao centro, mais ligações um setor apresenta e, consequentemente, é dotado de maior intensidade tecnológica e capacidade de espraiamento. Rodrik (2005) e Hausman, Hwang e Rodrik (2007) corroboram que quanto mais dinâmico e competitivo externamente é um setor, maior sua capacidade de gerar dinamismos internos. Da mesma forma, não se objetiva verificar a especificidade das atividades econômicas e sim, a análise estrutural da Economia brasileira em função de sua inserção

\footnotetext{
${ }^{3}$ As linhas "média-baixa, média-alta e alta" devem ser interpretadas através do eixo secundário (à direita) do Gráfico 6.
} 
nas cadeias globais de valor, de tal modo que não se faz necessário rotular as atividades em si, mas sim seus interligamentos.

Grafo 1 - Evolução do Product Space brasileiro entre 1970 e 2010

1970

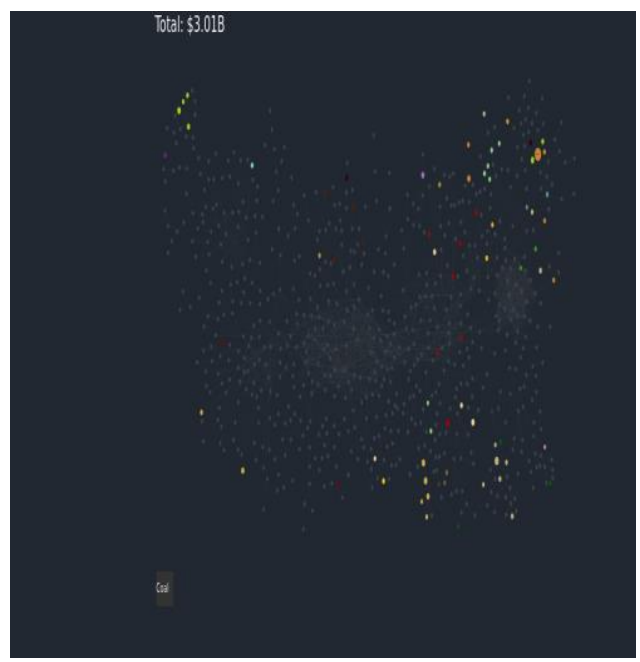

1990

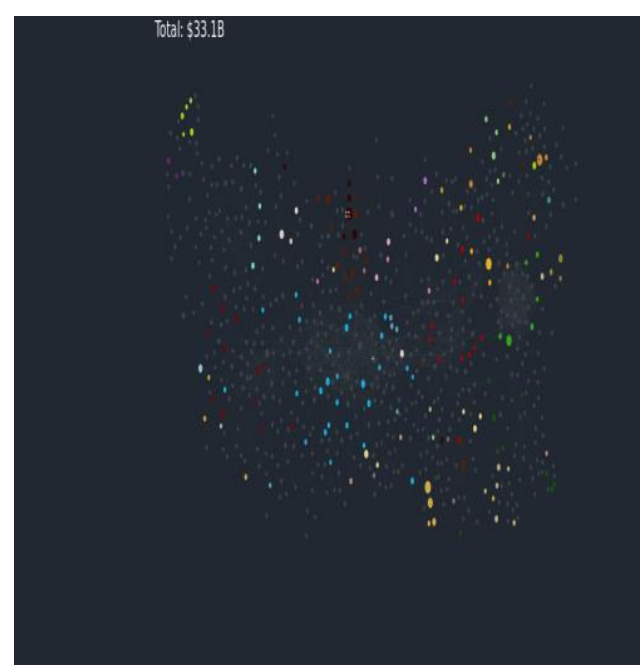

2010

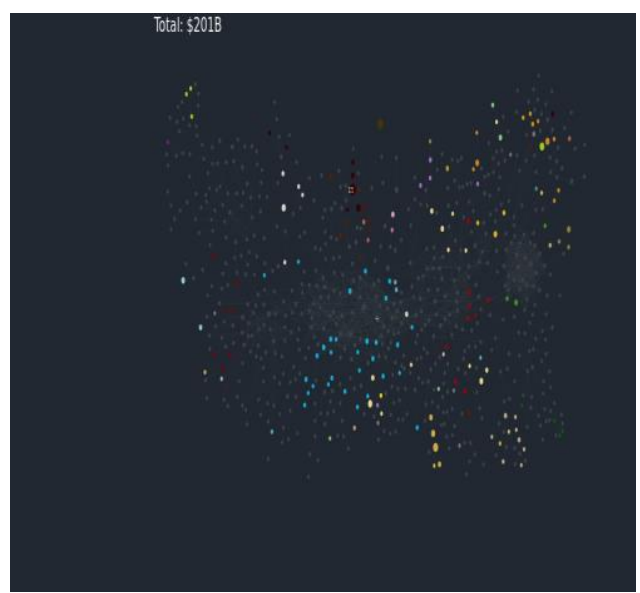

1980

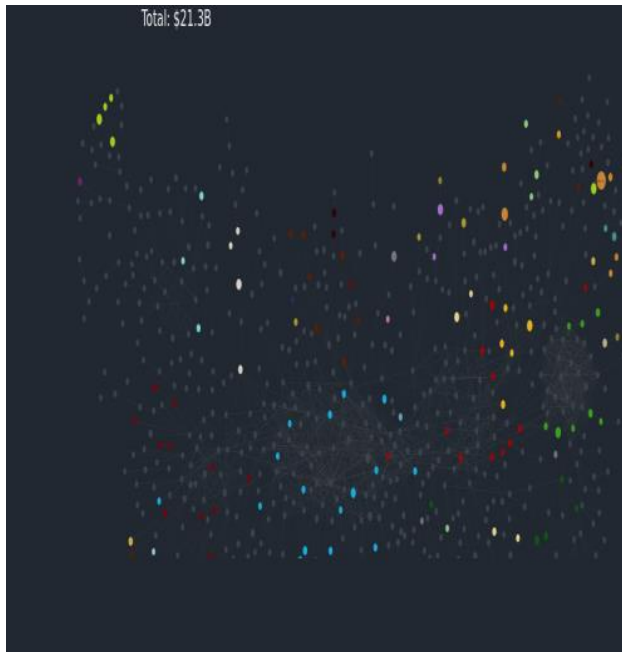

2000

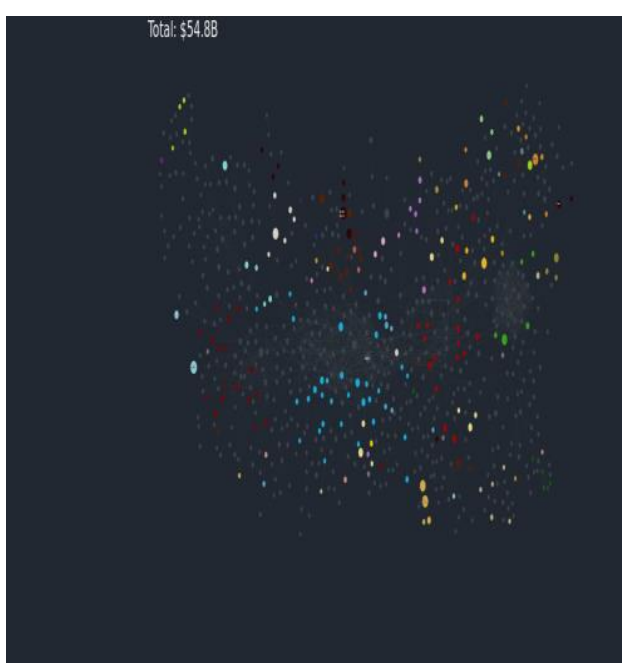

Fonte: Elaborado pelos autores com base em MIT (2017).

Estudos do CEPE [ISSN 1982-6729]. Santa Cruz do Sul, n. 46, p. 22-38, jul./dez. 2017. https://online.unisc.br/seer/index.php/cepe/index 
A análise dos product space propicia compreender que no Brasil houve significativa mudança estrutural entre 1970 e 1980. Todavia, pouco evoluiu entre 1980 e 2000, apresentando involução estrutural na última década analisada. No recorte de 1970, verifica-se a predominância de setores marginalizados, ou seja, com limitadas conexões e baixo grau de espraiamento, o que reflete a fragilidade da dinâmica das exportações brasileiras no período áureo da industrialização.

Apesar da não adequação do novo paradigma tecnológico da microeletrônica e manutenção da estrutura produtiva fordista, o Brasil dinamizou sua estrutura produtiva em um processo crescente até os anos 2000, período em que houve aumento relativo da pauta exportadora em bens minerais e agrícolas, de menor valor agregado. Verifica-se em 1990 a maior dinamicidade produtiva interna em função da inserção nas cadeias globais de valor, antecedente à descendência verificada posteriormente.

Por outra via, em 2010, tem-se uma estrutura de comércio exterior e de espraiamentos produtivos interna, similar à década de 1980, o que indica pouca ou nula interligação entre os avanços comerciais alcançados e maiores ganhos produtivos na estrutura industrial brasileiro na transição dos séculos.

\section{CONSIDERAÇÕES FINAIS}

A economia brasileira, durante o período que se seguiu o processo de industrialização pesada, pôde obter ganhos expressivos da participação da indústria de transformação no produto nacional. Isso ocorreu, contudo, a um preço elevado, em decorrência da imensa participação do capital internacional na composição da economia brasileira, principalmente, nos setores da indústria pesada. Durante o período caracterizado pela predominância do fordismo, a economia nacional funcionou de forma positiva em termos de aumento do produto.

Essa mesma participação crescente do capital externo na economia proporcionou o processo de queda da participação da indústria no PIB, haja vista que o capital internacional passa a se deslocar geograficamente com a reestruturação produtiva com a emergência da globalização e do paradigma microeletrônico. O processo de reestruturação produtiva global e a abertura econômica do Brasil nos anos 1990 conduzem a estrutura produtiva brasileira ao retorno do predomínio do setor primário-exportador.

A posição do Brasil dentro das cadeias globais de valor (CGV) apresenta grande participação em áreas intensivas em recursos naturais pelas suas peculiaridades da estrutura produtiva e, sobretudo, pela perda da participação da indústria de transformação no PIB que se acentuou com a reestruturação produtiva. A participação total de $40 \%$ na cadeia global de valor, com predomínio do indicador para frente, caracteriza o Brasil como um grande fornecedor de matérias primas de baixo valor adicionado.

A pauta de exportações brasileiras é marcada predominantemente por bens não industriais ou de baixa intensidade tecnológica, com significativa escassez de segmentos de maior tecnologia, o que reflete a fragilidade na inserção nas cadeias globais de valor, mesmo se considerado o período

Estudos do CEPE [ISSN 1982-6729]. Santa Cruz do Sul, n. 46, p. 22-38, jul./dez. 2017. https://online.unisc.br/seer/index.php/cepe/index 
áureo de sua industrialização sob a égide do paradigma fordista metalomecânico-químico, característico do século XX.

Da mesma maneira, a inserção do Brasil no cenário comercial internacional implicou em uma reestruturação produtiva interna, com avanços significativos alcançados a partir dos anos 1970, com a manutenção do paradigma tecnológico vigente e decadência na transição do século, em função da elevação das exportações de bens minerais e agrícolas e perda de participação relativa da indústria, tanto nas cadeias produtivas internas, quanto nas cadeias globais de valor.

Cabe, entretanto, a necessidade de uma análise mais profunda desse fenômeno. É fundamental compreender a posição de países com relativa estrutura produtiva semelhante a do Brasil nas cadeias globais de valor e analisar setorialmente essa posição. Por outro lado, é imprescindível a compreensão mais aprofundada do fenômeno da globalização produtiva e sua influência em economias periféricas, como a brasileira.

\section{REFERÊNCIAS}

AREND, M. 50 Anos de Industrialização do Brasil (1955-2005): uma Análise Evolucionária. Tese de Doutorado em Economia, Porto Alegre, UFRGS, 2009.

AREND, M.; FONSECA, P. C. D. Brasil (1955-2005): 25 anos de catching up, 25 anos de falling behind. Revista de Economia Política, v. 32, n. 1 (126), p. 33-54, 2012.

AREND, M.; SINGH, G. L.; BICHARRA, J. Mudança Estrutural Redutora da Produtividade: o falling behind brasileiro. In: 44 ENCONTRO NACIONAL DE ECONOMIA - ANPEC, 2016.

CASSIOLATO, J. E. Que futuro para a indústria brasileira? In: O Futuro da Indústria: Oportunidades e Desafios. A Reflexão da Universidade. Brasília, 2001.

FONSECA, P. C. D. Vargas: o capitalismo em construção. São Paulo: Brasiliense, 1989.

HAUSMANN, R.; HWUANG, J.; RODRIK, D. What you exports matters. Journal of Economic Growth, v. 12.1, p. 1-25. 2007.

HIDALGO, A. B.; FEISTEL, P. R. Mudanças na Estrutura do Comércio Exterior Brasileiro: Uma Análise sob a Ótica da Teoria de Heckscher-Ohlin. Revista Estudos Econômicos, v. 43, n. 1, p. 79108. São Paulo, 2013.

LAPLANE, M. O complexo eletrônico na dinâmica industrial dos anos oitenta. Campinas, tese (doutorado), Universidade Estadual de Campinas, 1992.

OCDE; OMC. Interconnected economies: benefiting from global value chains. Preliminary version. Genebra. 2013.

REIS, C. F. B.; ALMEIDA, J. S. G. A inserção do Brasil nas cadeias globais de valor comparativamente aos BRICS. Texto para Discussão. IE/UNICAMP, Campinas, n. 233, 2014.

REIS, C. F. B.; SOUZA, R. C. Produtividade e custo do trabalho na indústria de transformação no Brasil e em países selecionados: implicações para a inserção nas cadeias globais de valor. In: BARBOSA, N., et al. Industria e Desenvolvimento Produtivo no Brasil. Elsevier: Campus, 2015.

RODRIK, D. Growth strategies. Handbook of economic growth, v. 1, p. 967-1014, 2005.

SERRA, J. Ciclos e mudanças estruturais na economia brasileira do Pós-Guerra. In Belluzzo, L. G. M.; COUTINHO, R. (orgs.). Desenvolvimento capitalista no Brasil. São Paulo: Brasiliense, 1982.

Estudos do CEPE [ISSN 1982-6729]. Santa Cruz do Sul, n. 46, p. 22-38, jul./dez. 2017. https://online.unisc.br/seer/index.php/cepe/index 
VERSIANI, F.; SUZIGAN, W. O processo brasileiro de industrialização: uma visão geral. In: CONGRESSO INTERNACIONAL DE HISTÓRIA ECONÔMICA, 10, 1990.

Estudos do CEPE [ISSN 1982-6729]. Santa Cruz do Sul, n. 46, p. 22-38, jul./dez. 2017. https://online.unisc.br/seer/index.php/cepe/index 